\title{
Comparative Investigation of Gasoline-like Surrogate Fuels using 3D Computed Tomography
}

\author{
I.K. Karathanassis ${ }^{* 1,2}$, L. White ${ }^{1}$, P. Koukouvinis ${ }^{1,2}$, J. Hwang ${ }^{3}$, L. Pickett ${ }^{2}$, M. Gavaises ${ }^{1}$ \\ ${ }^{1}$ School of Mathematics Computer Science and Engineering, City, University of London, \\ Northampton Square, EC1V OHB, UK \\ ${ }^{2}$ Combustion Research Facility, Sandia National Laboratories, \\ 7011 East Ave, CA 94550, USA \\ ${ }^{3}$ Centre for Advanced Vehicular Systems (CAVS), Department of Mechanical Engineering, \\ Mississippi State University, Starkville, Mississippi 39762, USA \\ ${ }^{*}$ Corresponding author: ioannis.karathanassis@city.ac.uk
}

\begin{abstract}
The present work aims to investigate spray patterns of different fuel surrogates for gasoline using the standardized injector Spray $G$ of the Engine Combustion Network (ECN). More specifically, a 7- and a 9-component surrogate, named PACE-8 and PACE-20, respectively, have been comparatively evaluated against a certification gasoline fuel with $10 \%(\mathrm{w} / \mathrm{w})$ ethanol, RD5-87 (U.S. EPA Tier 3 certification fuel). High-speed visualisation experiments were conducted in the constant-flow spray chamber at the Combustion Research Facility. Ambient conditions of $0.5 \mathrm{bar} / 333 \mathrm{~K}$ and $6 \mathrm{bar} / 573 \mathrm{~K}$ were explored, covering the range between flash-boiling and pure evaporation. Injection pressure was set to 200 bar and the axisymmetric 8-hole injector was mounted on a rotating base, allowing the acquisition of images at $67,200 \mathrm{~Hz}$ from different viewing planes with the use of Diffuse Backlight Illumination (DBI). Acquisition of 72 viewing angles with an interval of $2.5^{\circ}$ enabled the reconstruction of the $3 \mathrm{D}$ liquid-phase volumetric distribution in the injected spray.
\end{abstract}

\section{Keywords}

Fuel Sprays, Injector Flows, Extinction Imaging, Renewable Fuels, Liquid Volume Fraction.

\section{Introduction}

Active research on clean combustion is necessitated by the stringent emissions legislation to be imposed in Europe and the U.S. within the next decade. From a broader perspective, societal and environmental concerns about the use of fossil fuels and after-effects on climate change dictate the development of internal combustion engines with enhanced fuel efficiency and reduced emissions primarily operating with renewable fuels. An understanding of GDI (Gasoline Direct Injection) spray dynamics is critical when addressing several topics in stateof-the-art engines including stratified/homogeneous charge strategies, advanced compression ignition, and avoidance of wall-wetting [1]. Poor fuel spray atomization and impingement on the cylinder walls lead to poor combustion efficiency and eventually increased particulate emissions [2].

High-fidelity, temporally-resolved visualisation of fuel sprays at realistic in-cylinder operating conditions constitutes a challenging task due to the multi-component nature and the uncertainty in the thermodynamic properties of commercial gasoline fuels [3], as well as to the highly-transient, three-dimensional morphology of the evolving two-phase mixture. The aim of this investigation is two-fold. Firstly, to introduce a novel many-view Computed-Tomography (CT) reconstruction technique combined with $\mathrm{DBI}$ extinction imaging that can quantify the 3D composition of asymmetric sprays. This approach differs from prior studies in that dozens of 
views (72) are used to reconstruct the liquid phase distribution in the spray, as compared to reconstruction using a handful of views that relied on geometric symmetry of the spray $[4,5]$. The second goal is to apply the technique to verify the capability of well-characterised surrogates to replicate the vaporisation and mixing behaviour of standardised gasolineethanol blends.

\section{Material and Methods}

Spray visualisation experiments were conducted in the continuous-flow spray chamber of the Combustion Research Facility [5], depicted in Figure 1. Fuel sprays are expelled by a Spray $G$ eight-hole injector into a nitrogen ambient with controlled pressure and temperature conditions. The rate of nitrogen flow is regulated by an electro-pneumatic flow controller and measured by two flow meters located at the vessel gas-feed and exhaust pipes. A bespoke oil-ring vacuum pump is used to reach sub-atmospheric conditions in the vessel. Nitrogen flow enters from the bottom side of the vessel, is heated by a bundle of heating coils (refer to Figure 1a) and its velocity and temperature fields are made uniform by a perforated diffuser before it enters the active vessel volume. The injected fuel and nitrogen mixture is exhausted through a pipe located at the top of the vessel. The ambient and injector conditions realised for the present experimental investigation are summarised in Table 1 and correspond to the $\mathrm{G} 2$ and G1 targets of an 8-hole injector, as described by the Engine Combustion Network [6]. However, an exception is that the injection duration in this study was $0.88 \mathrm{~ms}$ (about $11.6 \mathrm{mg}$ ) compared to the ECN standard of $0.78 \mathrm{~ms}(10 \mathrm{mg})$.

The liquid phase of the two-phase spray mixture was visualised using Diffused Back Illumination extinction (DBI) imaging [7]. A pulse-burst green LED served as the illumination source, while a Fresnel lens $(150 \mathrm{~mm}, \mathrm{f}=150 \mathrm{~mm})$ and an engineered diffuser $\left(20^{\circ}\right)$ pair were employed to create a homogeneous diffuse light field (Figure 1b). Multi-view spray-flow visualisation was made possible using an electronic stage rotated through 72 viewing angles at increments of $2.5^{\circ}$. High-speed images were recorded at $67,200 \mathrm{fps}$ with the active window being discretised by $512 \times 512$ pixels, resulting in a projected pixel size of $0.191 \mathrm{~mm}$.

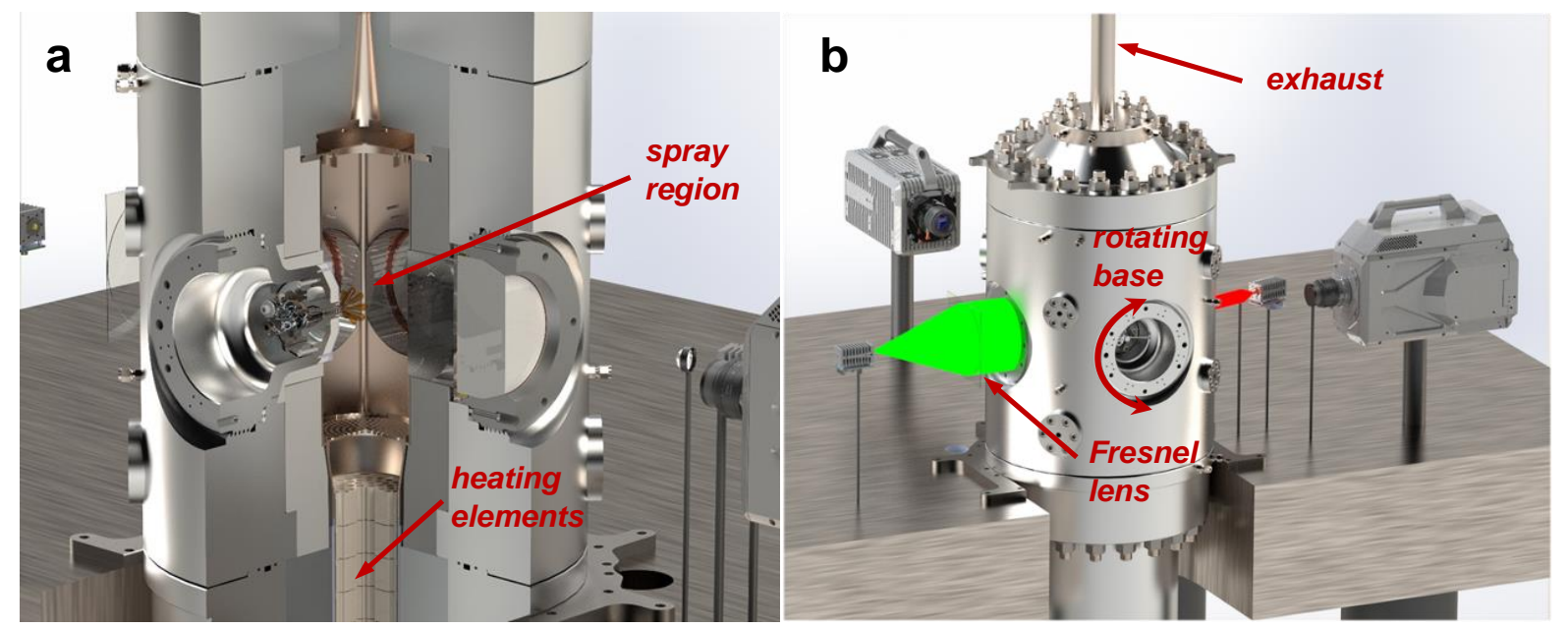

Figure 1. Constant-flow chamber employed for the experiments: (a) Section view illustrating the injector mounting configuration and the bundle of heating elements. (b) External view also depicting the optical set-up. 
Table 1 - Matrix of examined test cases.

\begin{tabular}{c|cccccc}
\hline Condition & $\mathbf{T}_{\text {amb }}[\mathrm{K}]$ & $\mathbf{p}_{\mathrm{amb}}[\mathrm{kPa}]$ & $\boldsymbol{\rho}_{\mathrm{amb}}\left[\mathrm{kg} / \mathbf{m}^{3}\right]$ & $\mathbf{T}_{\mathrm{f}}[\mathrm{K}]$ & $\mathbf{p}_{\text {inj }}[\mathrm{MPa}]$ & $\boldsymbol{\Delta} \mathbf{t}_{\text {inj }}[\mathrm{ms}]$ \\
\hline $\mathbf{G 1}$ & 573 & 600 & 3.5 & 363 & 20 & 0.88 \\
$\mathbf{G 2}$ & 333 & 50 & 0.5 & 363 & 20 & 0.88 \\
\hline
\end{tabular}

Extinction imaging facilitates quantification of liquid concentration in fuel sprays since the measured optical thickness $\tau$ can be explicitly correlated to the Projected Liquid Volume (PLV) along the line of sight. The optical thickness is obtained from raw images (Figure 2a) using the exponential attenuation law:

$$
I / I_{0}=e^{-\tau}
$$

where $I$ and $I_{0}$ refer to the attenuated light intensity due to the presence of liquid droplets and to the reference (background) intensity, respectively (Figure 2b). The measured optical thickness $\tau$ is related to the PLV, i.e. the integral of liquid volume fraction (LVF) along the cross-flow direction (Figure $2 \mathrm{c}$ ), as follows:

$$
\tau \frac{\pi d^{3} / 6}{C_{e x t}}=\int_{-y_{\infty}}^{y_{\infty}} L V F \cdot d y
$$

where $d(=7 \mu \mathrm{m})$ and $C_{\text {ext }}\left(=53.8 \cdot 10^{-6} \mathrm{~mm}^{2}\right)$ refer to a representative average value of the droplet diameters range in the spray region and to the extinction coefficient designated by the optical setup, respectively. The method followed to determine the values of $d$ and $C_{\text {ext }}$ are discussed in detail in [4]. The 72 PLV slices at each axial location were subsequently fed to a Filtered Back Projection algorithm, to create the time-resolved volumetric liquid volume fraction distributions of the spray plume. The iradon function embedded in Matlab was employed for the tomographic reconstruction using a Hamming filter parameter of 0.6.

a

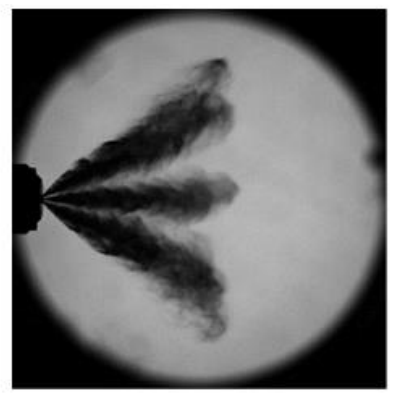

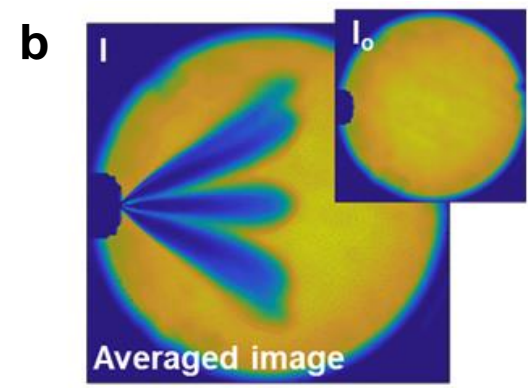
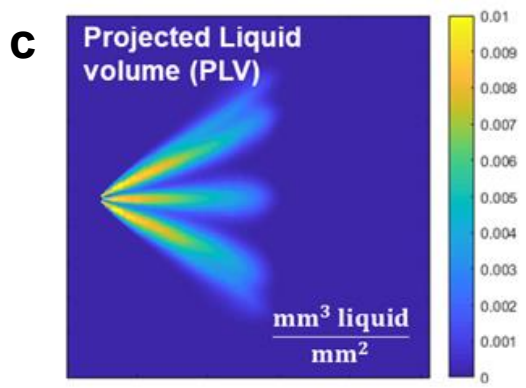

Figure 2. Basic steps of the methodology employed to extract quantitative Projected Liquid Volume (PLV) values from DBI images: (a) raw image, (b) normalised image against background and (c) PLV contour plot.

The rationale behind the formulation of the PACE-8 and PACE-20 samples examined in this study is to introduce gasoline surrogates of well-defined composition (refer to Table 2) to be used for overlapping research between different laboratories and institutions. The two surrogate fuels have met RON/MON and other combustion targets in comparison to a reference multi-component gasoline/ethanol blend (referred to as RD5-87), representative of the $98 \%$ of commercial gasoline available in the U.S. market. The effects of ethanol content are important to consider in spray studies as it has been shown that E10 fuels form non-ideal mixtures with increased volatility compared to the two blended constituents, leading to an 
increased propensity for flashing [8]. The distillation curves of the examined samples are shown in Figure 3, demonstrating that a similar evaporation behaviour should be expected, with the PACE-20 sample consistently being slightly more volatile in the temperature range of $90-120^{\circ} \mathrm{C}$.

\section{Results and Discussion}

The 3D spray topology evolution with time for the $\mathrm{G} 2$ and $\mathrm{G} 1$ conditions, depicted in Figures 4a-b, was created from the tomographic reconstruction of averaged PLV slices acquired at the 72 viewing planes for each time instance of the injection event. Each PLV time instance was an ensemble average from 25 injection events. Full spray-plume collapse into a single mushroom-shaped structure can be seen in Figure 4a for the flash boiling-condition G2. On the contrary, discernible plumes are evident for the G1 condition, Figure 4b, which is indicative of pure spray evaporation at a high-temperature environment. The three-dimensional nature of the flow is captured by the reconstructed volumes, as demonstrated by the time instances corresponding to $0.64 \mathrm{~ms}$ and $1.04 \mathrm{~ms}$ in Figure 4a. These reveal topological perturbations in the plume 'head' that clearly deviate from axi-symmetry.

Table 2 - Liquid vol. \% of the surrogate fuels.

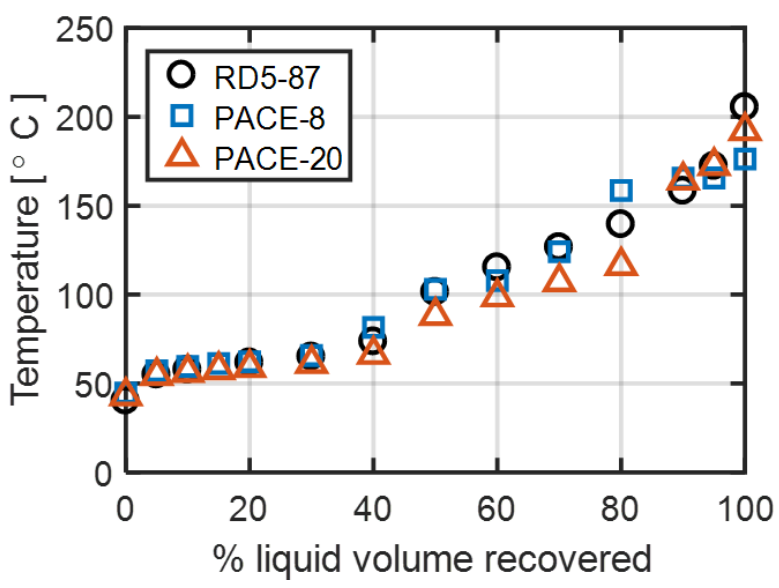

\begin{tabular}{lcc}
\hline component & PACE-8 & PACE-20 \\
\cline { 1 - 2 } ethanol & 0.0939 & 0.0955 \\
n-pentane & - & 0.1395 \\
iso-pentane & 0.1036 & - \\
cyclopentane & 0.0834 & 0.1050 \\
1-hexene & 0.0536 & 0.0541 \\
n-heptane & 0.1684 & 0.1153 \\
toluene & - & 0.0919 \\
iso-octane & 0.2451 & 0.2505 \\
1,2,4-trimethylbenzene & 0.2520 & 0.1187 \\
tetralin & - & 0.0295 \\
\hline
\end{tabular}

Figure 3. Distillation curves for the examined fuel samples (D86 experimental data).

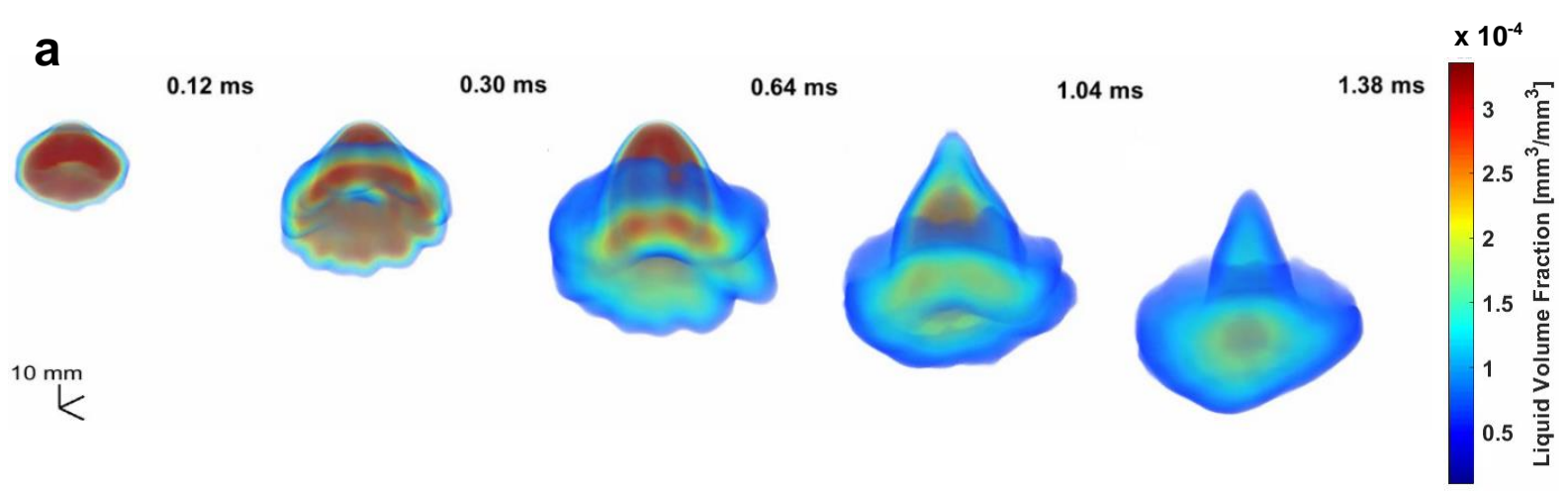


b

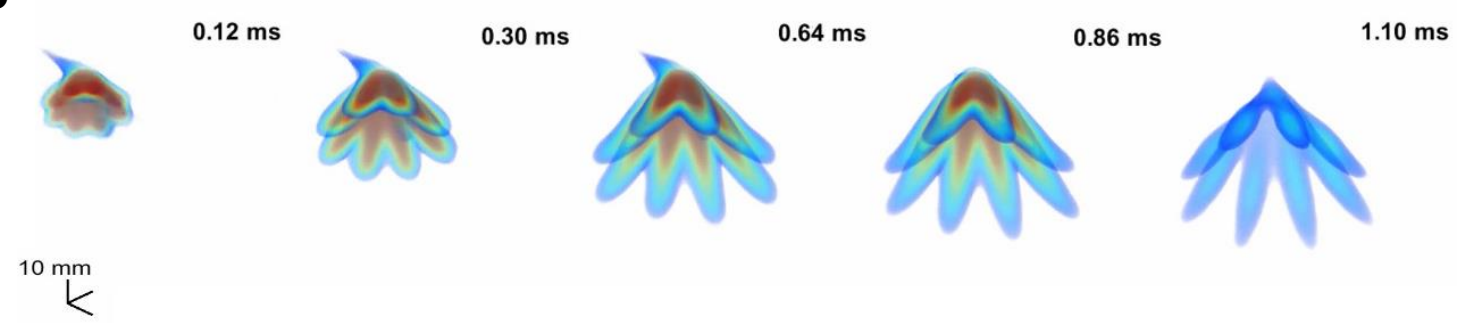

Figure 4. Temporal evolution of the 3D spray topology (PACE-8): (a) G2 and (b) G1 conditions.

Plume to plume variations are evident in the cross-flow contour plots at two axial locations, $15 \mathrm{~mm}$ (Figure 5a) and 30mm (Figure 5b) downstream the injector outlet at $0.7 \mathrm{~ms}$ aSol. Referring to the Figure 5a, the eight discrete plumes can be discerned for the evaporating G1 condition. The general morphology of the plumes is similar, nevertheless plumes 1-3 exhibit higher liquid volume fraction values than the rest. Differences are accentuated in the $30 \mathrm{~mm}$ plane, where a clear lag of plumes 5,7 , and 8 is evident as they exhibit low liquid masses in the slice plane near end of injection. Variations in the temporal evolution of discrete injector plumes are mainly due to the complex flow within the internal geometry of the device, where, depending on the ambient conditions, transient flash boiling (for G2 condition) or cavitation regimes (for $\mathrm{G} 1$ condition) set in [9]. Furthermore, machining imperfections in the injector body can cause differences in the injected plumes [10] that can be amplified by shear-flow induced instabilities at the two-phase interfaces.

a

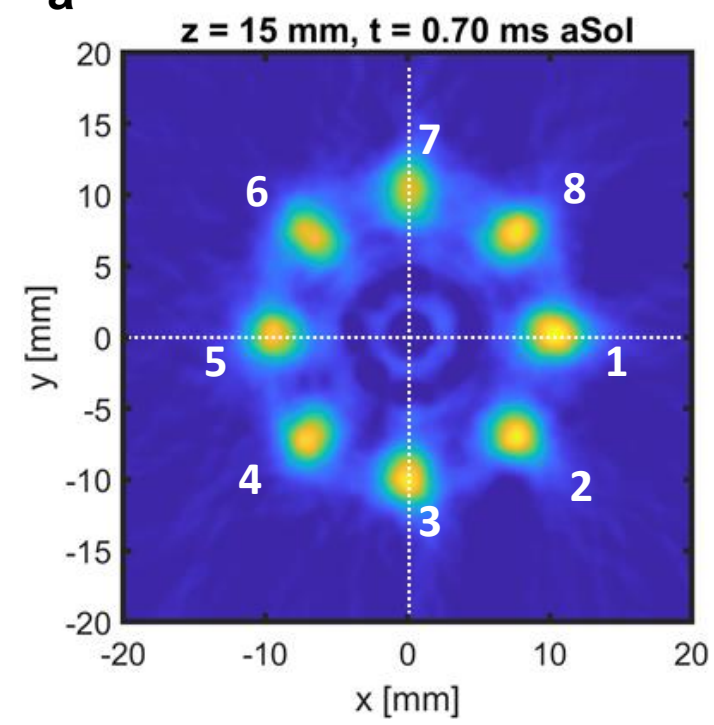

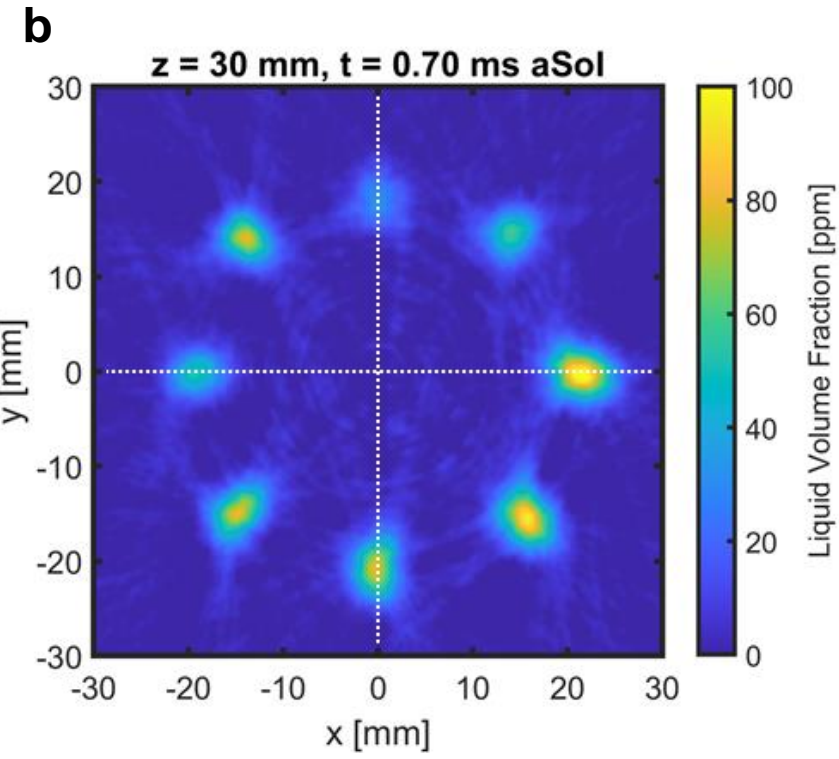

Figure 5. LVF contour plots at cross-flow planes (a) $15 \mathrm{~mm}$ and (b) $30 \mathrm{~mm}$ downstream of the injector outlet (G1 condition).

The discrepancies between different plumes are quantified in Figure 6 which depicts the radial LVF distribution for the G1 condition at cross-flow planes $15 \mathrm{~mm}$ (Figure 6a) and $30 \mathrm{~mm}$ (Figure 6b) downstream the injector outlet, refer also to Figure $6 \mathrm{c}$ for the locations of the slice planes. Faded lines correspond to LVF values for each plume, whereas the bold line corresponds to average values for all eight plumes. As can be seen, variations are moderate in the $15 \mathrm{~mm}$-plane with peak LVF values for all plumes lying in the range between 400-500 ppm. In contrast, further downstream at a location of substantial vaporisation, peak LVF values 
exhibit considerable variation, between 30 and $100 \mathrm{ppm}$. The flow three-dimensionality is clearly obscured if only the averaged distribution is considered. It is also interesting to notice that, apart from peak LVF values, the distribution topology corresponding to each plume is also variable, which is illustrative of the difference in shape of the spray 'imprints' on the slice plane.

a

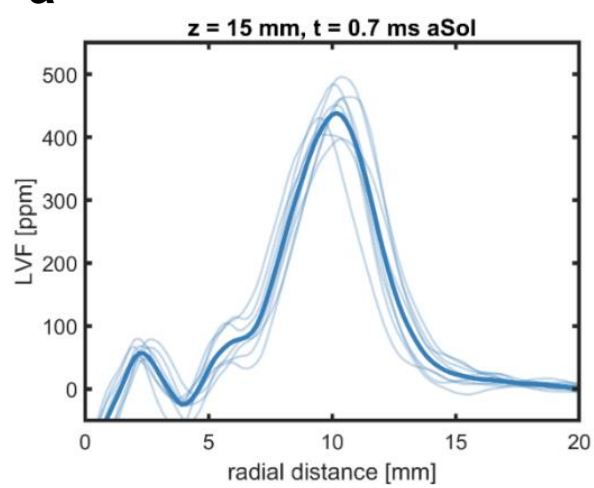

b

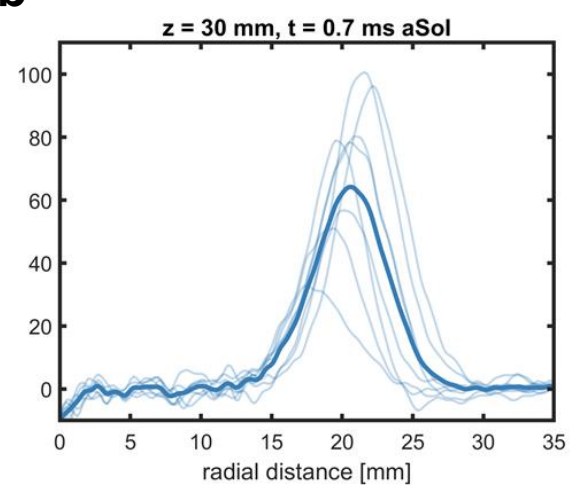

C

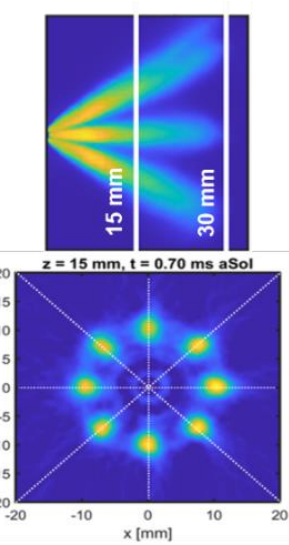

Figure 6. Radial LVF distribution at cross-flow planes (a) $15 \mathrm{~mm}$ and (b) $30 \mathrm{~mm}$ downstream of the injector outlet (G1 condition). (c) The locations of slice planes and plotting directions

A PLV threshold can serve as an indicator for the overall spray-plume liquid phase penetration. The ECN recommends two threshold values of either $0.2 \cdot 10^{-3}$ or $2 \cdot 10^{-3} \mathrm{~mm}^{3}$ (liquid) $/ \mathrm{mm}^{2}$ to estimate penetration. Figure 7 presents the relevant time history for the examined G2 (Figure 7a) and G1 (Figure 7b) conditions using both thresholds. The liquid penetration is much larger for the G2 condition, almost double the respective value for the G1 condition, and in fact, reaches the limit of the visualisation window. The collapse of the plumes in the G2 condition onto the injector axis leads to a denser liquid column that is more resistant to evaporation, producing greater penetration. In contrast, liquid vaporises rapidly due to the hightemperature environment corresponding to the $\mathrm{G} 1$ condition, resulting in reduced penetration. More importantly, it is evident that the two surrogate fuels successfully replicate the macroscopic behaviour of the RD5-87 gasoline in terms of macroscopic spray behaviour for a wide range of flow conditions ranging from flash boiling to high pressure and temperature environment.

a

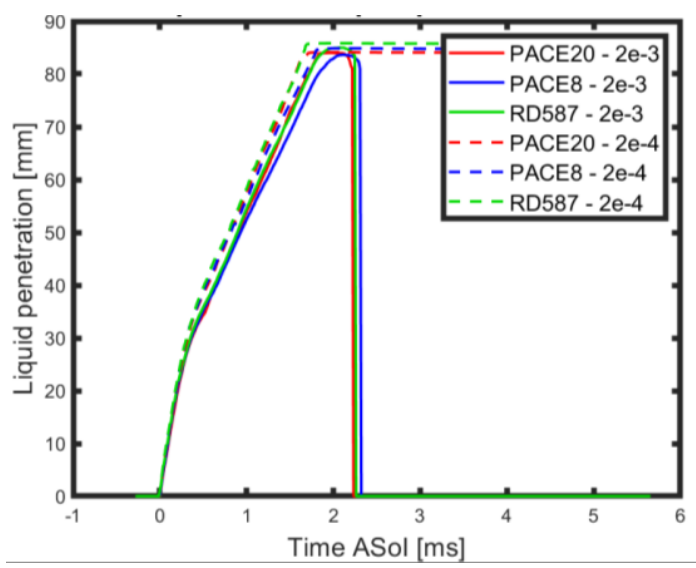

b

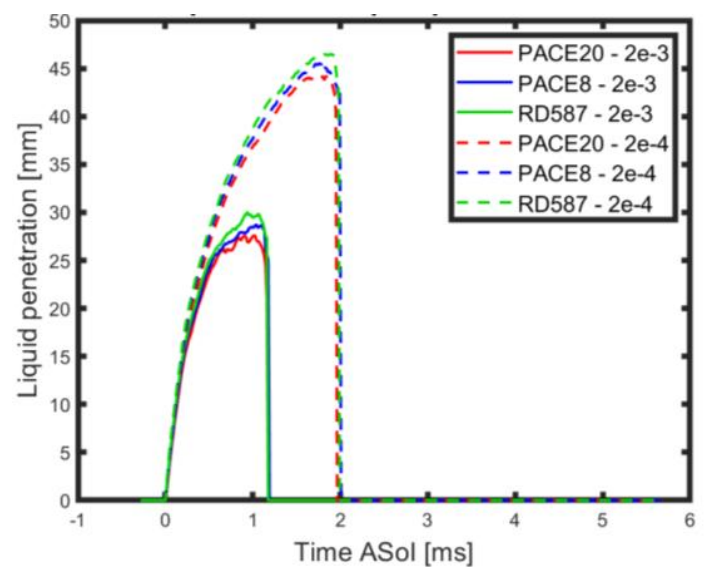

Figure 7. Liquid-phase penetration of the examined gasoline fuel samples for (a) G2 and (b) G1 conditions. 
A quantitative comparison, in terms of LVF, between the two surrogate fuels and the RD5-87 gasoline is shown in Figure 8 with reference to the G2 (Figure 8a) and G1 conditions (Figure $8 b)$. The panels of Figures $8 a-b$ depict representative time instances near the end of the injection event with the LVF radial distribution averaged across all eight plumes. The plots refer to a cross-flow plane $30 \mathrm{~mm}$ downstream of the injector tip. The distribution for the G2 condition exhibits high LVF values at radial locations close to the axis of symmetry. This trend is due to the full plume collapse to a single, three-dimensional structure (refer to Figure 4a) that propagates along the injector centreline. In contrast, the LVF distribution corresponding to the G1 condition exhibits peak LVF values at a radial location approximately equal to 20 $\mathrm{mm}$ throughout the injection event. This is illustrative of the fact that the spray plumes remain discrete and relatively steady throughout the injection event. In addition, the obtained LVF values are much smaller for the G1 compared to the $\mathrm{G} 2$ condition due to increased evaporation resulting from the higher ambient temperature, i.e. $573 \mathrm{~K}$ compared to $333 \mathrm{~K}$, and the collapsed state of the $\mathrm{G} 2$ spray. With respect to the capability of fuel surrogates to replicate the behaviour of the reference gasoline, it is clearly demonstrated that this is accomplished for both flash boiling and evaporative conditions since, like overall penetration, the differences in the LVF distributions of the three samples are negligible.

a
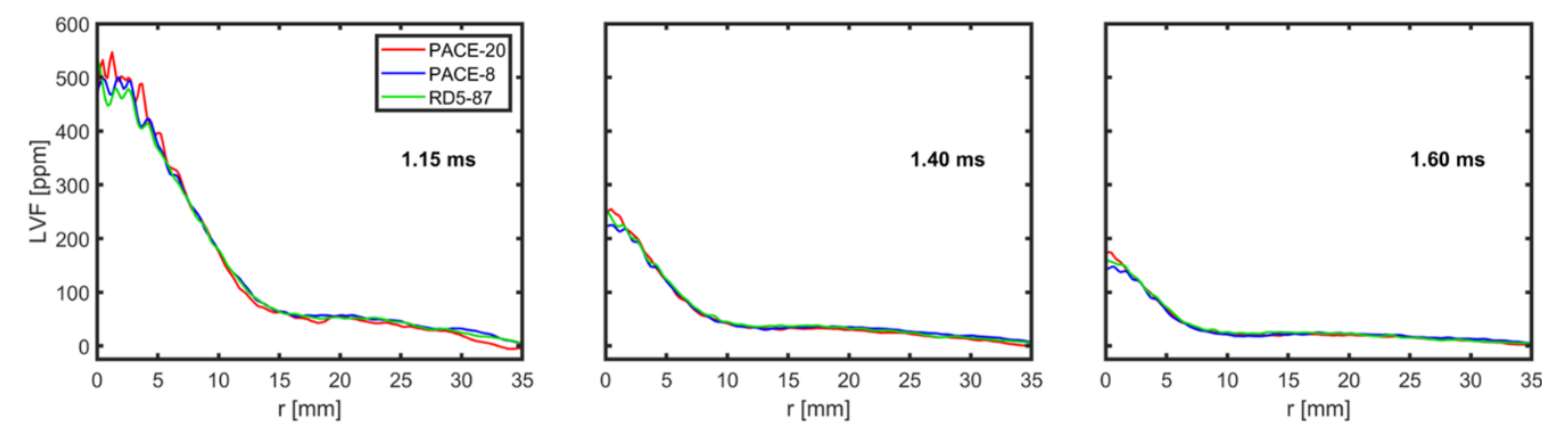

b
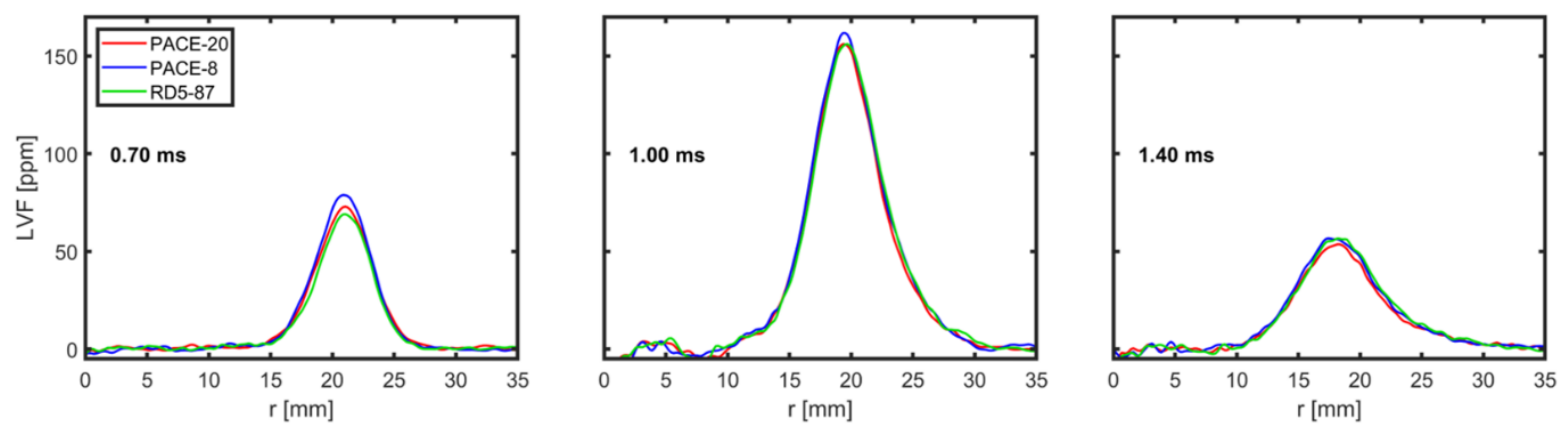

Figure 8. Radial distribution of averaged LVF for different time instances at a cross-flow plane 30mm downstream the injector outlet: (a) G2, (b) G1 condition.

\section{Conclusions}

This work contributes to the understanding of GDI technology by experimentally measuring the evolution of liquid distributions in free GDI sprays in both space and time through CT reconstruction of Diffuse Back-Illuminated extinction imaging. The implemented experimental technique can resolve plume-to-plume variations in quantitative liquid distribution and provides a valuable tool for comparative spray investigations and CFD validation. These results demonstrate similar spray behaviour between the tested gasoline surrogates and the 
certification gasoline sample. This approach facilitates the generation of recommendations regarding gasoline surrogates for future ECN Spray G research, which includes spray evaporation and combustion studies.

\title{
Acknowledgments
}

Experiments were performed at the Combustion Research Facility, Sandia National Laboratories (SNL), a multi-mission laboratory managed and operated by National Technology and Engineering Solutions for Sandia LLC, a wholly-owned subsidiary of Honeywell International, Inc., for the U.S. Department of Energy's National Nuclear Security Administration under contract DE-NA0003525. Funding from the EC Marie Skłodowska-Curie Global Fellowships AHEAD (IK, Grant No. 794831) and UNIFIED (PK, Grant No. 748784) is acknowledged, which also supported the international visiting program of I.K. Karathanassis and P. Koukouvinis at SNL.

\author{
Nomenclature \\ $\mathrm{C}_{\text {ext }}$ extinction cross-section $\left[\mathrm{m}^{2}\right]$ \\ d droplet diameter [m] \\ I transmitted intensity [-] \\ Io normalized baseline intensity [-] \\ LVF Liquid Volume Fraction [-] \\ $\tau \quad$ optical thickness [-]
}

\section{References}

[1] Dec, J. E., Dernotte, J., Ji, C., 2017, SAE International Journal of Engines, 10(3).

[2] Tang, Q., Liu, H., Li, M., Yao, M., 2017, Applied Energy, 185, pp. 708-719.

[3] Neroorkar, K., Schmidt, D., 2011, Fuel, 90, pp. 665-673.

[4] Weiss, L., Wensing, M., Hwang, J., Pickett, L. M., Skeen, S. A., 2020, Experiments in Fluids, pp. 1-17.

[5] Hwang, J., Weiss, L., Karathanassis, I. K., Koukouvinis, P., Pickett, L. M., Skeen, S. A., 2020, Fuel, 280, p. 118359.

[6] Engine Combustion Network, Sandia National Laboratories, https://ecn.sandia.gov/

[7] Westlye, F. R., Penney, K., Ivarsson, A., Pickett, L. M., Manin, J., Skeen, S. A., 2017, Applied Optics, 56, p. 5028.

[8] Andersen, V. F., Anderson, J. E., Wallington, T. J., Mueller, S. A., Nielsen, O. J., 2010, Energy and Fuels, 24, pp. 3647-3654.

[9] Baldwin, E. T., Grover, R. O., Parrish, S. E., Duke, D. J., Matusik, K. E., Powell, C. F., Kastengren, A. L., Schmidt, D. P., 2016, International Journal of Multiphase Flow, 87, pp. 90-101.

[10] Duke, D. J., Kastengren, A. L., Matusik, K. E., Swantek, A. B., Powell, C. F., Payri, R., Vaquerizo, D., Itani, L., Bruneaux, G., Grover, R. O., Parrish, S., Markle, L., Schmidt, D., Manin, J., Skeen, S. A., Pickett, L. M., 2017, Experimental Thermal and Fluid Science, 88, pp. 608-621. 